(2) Open Access Full Text Article

ORIGINALRESEARCH

\title{
Impacts of Hypoglycemia in At-Risk Infants on Admissions to Level-3 Neonatal Units in a Tertiary-Care Hospital
}

\author{
Hala Alasaad' \\ Ela Beyyumi ${ }^{\prime}$ \\ Taoufik Zoubeidi ${ }^{2}$ \\ Nusrat Khan' \\ Omar Abu-Sa'da' \\ Mohammad Khassawneh' \\ Abdul-Kader Souid ${ }^{3}$ \\ 'Department of Pediatrics, Tawam Hospital, \\ Al Ain, Abu Dhabi, United Arab Emirates; \\ 2Department of Statistics, College of \\ Business and Economics, UAE University, Al \\ Ain, Abu Dhabi, United Arab Emirates; \\ ${ }^{3}$ Department of Pediatrics, College of \\ Medicine and Health Sciences, UAE \\ University, Al Ain, Abu Dhabi, United Arab \\ Emirates
}

Introduction: Hypoglycemia is frequent in level-1 postnatal units (PNU), which can result in many transfers to the level-3 neonatal unit (NNU).

Objectives: This study reports on hypoglycemia (capillary blood glucose $<2.5 \mathrm{mmol} / \mathrm{L}$ in the first $24 \mathrm{~h}$ ) in at-risk infants. Its main objective was to evaluate the impact of hypoglycemia in level-1 PNU on level-3 NNU admissions.

Methods: The study was retrospective, conducted between January 01, 2018 and December 31, 2018. Inclusion criteria were infants in the PNU who were: 1) late-preterm (35 $\leq$ weeks' gestation <37), 2) infants-of-diabetic mothers (IDM), and/or 3) low (2.0-2.5 kg) or high $(>4.0 \mathrm{~kg})$ birthweight.

Results: Of the 3192 deliveries, 983 (31\%) were eligible for study enrollment; 77\% were IDM and 19\% late-preterm. A total of $192(19.5 \%)$ newborns had hypoglycemia in the first $4 \mathrm{~h}$ and 42 (4.3\%) within 4-24 h. Twenty-two (2.2\%) newborns were transferred to NNU, 17 in first $4 \mathrm{~h}$ and five within 4-24 h. Overall, independent predictors of NNU transfer were late-preterm, cesarean delivery, and glucose measurement $<1.5 \mathrm{~h}(P \leq 0.019)$. Independent predictors of hypoglycemia in the first $4 \mathrm{~h}$ were late-preterm, cesarean delivery, glucose measurement before feeding, and glucose measurement $<1.5 \mathrm{~h}(P \leq 0.045)$. The independent predictor of hypoglycemia within $4-24 \mathrm{~h}$ was cesarean delivery $(P=0.017)$. Ten neonates had blood glucose $\leq 1.0 \mathrm{mmol} / \mathrm{L}$; they all required NNU transfer for intravenous glucose.

Conclusion: This study shows frequent low glucose readings in these infants (overall prevalence, $23.8 \%$ ) and confirms the need for clinical observation and regular monitoring. It is prudent to initiate and maintain proper feeding and to adhere to evidence-based guidelines.

Keywords: late preterm, cesarean delivery, IDM, neonatal units, newborn feeding

\section{Introduction}

There are numerous risk factors associated with neonatal hypoglycemia. They commonly include maternal conditions, such as obesity, diabetes, hypertension, medications (eg, intravenous glucose, beta-blockers, and beta-agonist tocolytics), substance use, pre-eclampsia, and gestational diabetes. Newborn conditions include prematurity, cesarean delivery, inappropriate birthweight, small-for-gestational-age (SGA), intrauterine growth restriction (IUGR), discordant twins, polycythemia, inborn error of metabolism (IEM), genetic syndromes, endocrine abnormalities, respiratory distress, and other perinatal complications (including a 5-min Apgar score $<7$ ). ${ }^{1-4}$

The definition of hypoglycemia is arbitrary and varies with age. ${ }^{5}$ Thus, there are several guidelines for screening and managing neonatal hypoglycemia. ${ }^{5,6}$ The
Correspondence: Hala Alasaad

Department of Pediatrics, Tawam

Hospital, Al Ain, Abu Dhabi, United Arab

Emirates

Tel +97| 52-678448 I

Email hasaad@seha.ae 
Canadian Pediatric Society considers blood glucose $<2.6$ $\mathrm{mmol} / \mathrm{L}$ in the first $72 \mathrm{~h}$ as "transitional hypoglycemia" and $<3.3 \mathrm{mmol} / \mathrm{L}$ after $72 \mathrm{~h}$ as "persistent hypoglycemia". 6 Reference values that specifically cover the first $4 \mathrm{~h}$ of life and extend beyond $24 \mathrm{~h}$ are highly needed in both healthy and at-risk newborns.

The level-3 neonatal units (NNU) of tertiary referral hospitals are often hindered by a large number of high-risk pregnancies and the associated adverse events on the newborn. Many of these infants may fit admission to a lowerlevel nursery, such as level-1 postnatal units (PNU). Adhering to evidence-based procedures in the PNU will likely lower the rate of neonatal complications, including the transfer to NNU. ${ }^{1-3}$

For at-risk infants, relatively simple interventions have been shown to reduce the transfer to NNU due to hypoglycemia. ${ }^{2}$ This study investigates central variables (late-preterm, maternal/gestational diabetes, and inappropriate birthweight) that may increase the risk of hypoglycemia, and their contributions to NNU transfer. Core preventive measures for such infants, such as standard newborn care, initiating and maintaining proper feeding (assuring adequate caloric intake), regular glucose monitoring, and risk stratification are analyzed. ${ }^{7}$ This report also highlights concerns that require improvements in both monitoring and managing low glucose readings in the PNU, considering the well-documented adverse neurodevelopmental outcome of hypoglycemia..$^{8-11}$

\section{Methods}

This study was a retrospective chart review of the newborn records, and was approved by 'Tawam Human Research Ethics Committee (AA/AJ/662). This committee waivers the consent for research for approved retrospective chart reviews. The study was conducted according to the $\mathrm{ICH}-$ GCP guidelines, and the patient information was protected according to the guidelines of the declaration of Helsinki. During the study period (January 01, 2018 to December 31, 2018), there were 3192 deliveries at Tawam Hospital (the only tertiary-care center in Al Ain, Abu Dhabi, United Arab Emirates). Of these, approximately 600 neonates were directly admitted to the level-3 NNU. The hospital did not have a transitional/ level-2 nursery; thus, escalation of hypoglycemia management (eg, nasogastric tube feeding and intravenous glucose infusion) required NNU admission.

The postnatal unit (PNU, a level-1 nursery) encouraged rooming-in practice, breastfeeding in the first hour of life and, when possible, offered limited (approximately one hour) skin-to-skin contact. Asymptomatic infants at risk of hypoglycemia (late preterm, IDM, and/or inappropriate birthweight) routinely received regular glucose monitoring per the American Academy of Pediatrics (AAP) protocol; ${ }^{1}$ please also see Supplementary File. Newborns $<35$ weeks' gestation, $<2.0 \mathrm{~kg}$ birthweight, or having symptoms (clinical problems) were directly (immediately after birth) admitted to the level-3 NNU.

Study eligibility was all newborns with birthweight $\geq 2.0 \mathrm{~kg}$ who were admitted immediately after delivery to the PNU and had at least one of the following risk factors for hypoglycemia (defined as, capillary blood glucose $<2.5$ $\mathrm{mmol} / \mathrm{L}$ ): (1) Late preterm (gestational age, $35^{0 / 7}$ to $36^{0 / 7}$ weeks); (2) IDM; and/or (3) Low (2.0 to $2.5 \mathrm{~kg}$ ) or high birthweight $(>4.0 \mathrm{~kg})$. Gestational age (based on the last menstrual period or early trimester ultrasound dating) and birthweight were obtained from the labor and delivery records. Unless medically indicated, intravenous glucosecontaining solutions were not routinely administered to the mothers in our labor and delivery unit. Intravenous glucose solutions, however, were used for cesarean deliveries.

The gestational or maternal diabetes status was obtained from the labor and delivery records. All pregnancies were screened for gestational diabetes between 24 and 28 weeks' gestation, using the clinical guidelines and standardized practices recommended by the American College of Obstetricians and Gynecologists. ${ }^{22}$ The "oral glucose tolerance test" includes 100-g sugar. A diagnosis of gestational diabetes was made if the fasting blood glucose was $\geq 5.3$ $\mathrm{mmol} / \mathrm{L}$, one-hour blood glucose $\geq 10.0 \mathrm{mmol} / \mathrm{L}$, two-hour blood glucose $\geq 8.6 \mathrm{mmol} / \mathrm{L}$, or three-hour blood glucose $\geq 7.8 \mathrm{mmol} / \mathrm{L}$. Mothers with confirmed gestational diabetes were advised on self-monitoring, ideal levels of control, and pregnancy risks.

First breastfeeding typically occurred in the labor and delivery unit at 30 to $60 \mathrm{~min}$ after birth. Maternal conditions that required postpartum management occasionally made formula feeding the alternative option for some atrisk infants. A local guideline (2020, "screening for and management of neonatal hypoglycemia in at-risk infants") is provided as Supplementary File. Briefly, first glucose measurement should be performed $1.5 \mathrm{~h}$ after birth (30 to $60 \mathrm{~min}$ after feeding). For the neonates with large-forgestational-age (LGA) or IDM, glucose monitoring should be every $3 \mathrm{~h}$ for $12 \mathrm{~h}$. For the neonates with SGA or latepreterm, glucose monitoring should be every $3 \mathrm{~h}$ for 24 
h. Notifiable glucose values were $<2.5 \mathrm{mmol} / \mathrm{L}$, regardless of its time or clinical variables.

Capillary blood was typically collected by a warmed heel prick using the nonenzymatic Accu-Chek ${ }^{\circledR}$ Inform II System (Blood Glucose Monitoring System, Roche Diagnostics). The lowest limit of detection was 0.61 $\mathrm{mmol} / \mathrm{L}(11 \mathrm{mg} / \mathrm{dL})$; unfortunately, values between 0.61 and $1.0 \mathrm{mmol} / \mathrm{L}$ were rounded up in the medical records to $1.0 \mathrm{mmol} / \mathrm{L}$ (occurred in 10 of the 983 studied newborns). Blood glucose $<2.5 \mathrm{mmol} / \mathrm{L}$ was not routinely confirmed by an enzymatic method in the laboratory or a blood gas analyzer. The time and result of glucose measurements were automatically linked to the electronic medical record; thus, these values were available for all studied newborns.

The time of first feeding was charted manually by the nurses, which was available in only 574 (58\%) newborns. For the remaining 409 (42\%) newborns, the status of being fed $\leq 1.0 \mathrm{~h}$ or $>1.0 \mathrm{~h}$ after birth was charted. It is worth emphasizing that the data reported here were obtained from reviewing the newborn records, which did not include all important (relevant) maternal conditions.

\section{Statistics}

The analysis was performed on SPSS, version 20. Pearson chisquare test was used to evaluate the frequency distribution of certain variables as a function of blood glucose. Backward multiple logistic regression models (likelihood ratio) were used to evaluate hypoglycemia (blood glucose $<2.5 \mathrm{mmol} / \mathrm{L}$ in the first $4 \mathrm{~h}$ as well as 4 to $24 \mathrm{~h}$ ) and NNU transfer versus various predictors. The significant variables in simple logistic regressions of hypoglycemic status were entered in the backward multiple logistic regression models. $P<0.05$ was considered significant.

\section{Results}

Of the 3192 deliveries, 983 (31\%) were eligible for study enrollment and were included. Their characteristics are in Table 1. Seventy-seven percent of the newborns were IDM and $19 \%$ were late preterm. Serial capillary blood glucose readings were available in 917 (93\%) newborns, who completed the scheduled screening described in Methods and Supplementary File.

\section{NNU Admissions}

A total of 192 (19.5\%) newborns had blood glucose $<2.5$ $\mathrm{mmol} / \mathrm{L}$ in the first $4 \mathrm{~h}$ (early hypoglycemia). Of these, 17 were transferred to the NNU for "low blood glucose readings, and not responding to the local feeding trial" (giving
Table I Study Sample Population, $\mathrm{n}=983$ (All At-Risk Newborns Who Were Admitted to the Postnatal Unit in 2018)

\begin{tabular}{|c|c|}
\hline Females & $460(47 \%)$ \\
\hline Vaginal delivery & $647(66 \%)$ \\
\hline \multicolumn{2}{|l|}{ Late preterm versus term ${ }^{\mathrm{a}}$} \\
\hline Late preterm & $189(19 \%)$ \\
\hline Term & $794(81 \%)$ \\
\hline Infant of diabetic mother (IDM) & $754(77 \%)$ \\
\hline \multicolumn{2}{|l|}{ Birthweights (kg) } \\
\hline Mean $\pm S D$ & $3.1 \pm 0.5$ \\
\hline Median & 3.1 \\
\hline Range & 2.0 to 4.6 \\
\hline \multicolumn{2}{|l|}{ Birthweight categories } \\
\hline 2.0 to $<2.5 \mathrm{~kg}$ & $60(6 \%)$ \\
\hline 2.5 to $4.0 \mathrm{~kg}$ & $739(75 \%)$ \\
\hline$>4.0 \mathrm{~kg}$ & $184(19 \%)$ \\
\hline Blood glucose $<2.5 \mathrm{mmol} / \mathrm{L}$ within $4 \mathrm{~h}$ of life ${ }^{\mathrm{b}}$ & $193(19 \%)$ \\
\hline Blood glucose $<2.5 \mathrm{mmol} / \mathrm{L}$ between 4 and $24 \mathrm{~h}$ of life ${ }^{c}$ & $42(4 \%)$ \\
\hline \multicolumn{2}{|l|}{$\mathrm{NNU}$ transfer within $24 \mathrm{~h}^{\mathrm{d}}$} \\
\hline Total & $22(2 \%)$ \\
\hline Within first $4 \mathrm{~h}$ & 17 of 22 \\
\hline Within 4 to $24 \mathrm{~h}$ & 5 of 22 \\
\hline IDM & 19 of 22 \\
\hline Late preterm & 6 of 22 \\
\hline First feeding $\leq 1.0 \mathrm{~h}$ & $688(70 \%)$ \\
\hline First blood glucose measurement $>1.5 \mathrm{~h}$ & $764(78 \%)$ \\
\hline First feeding before blood glucose measurement ${ }^{\mathrm{e}}$ & $791(80 \%)$ \\
\hline \multicolumn{2}{|l|}{ Type of first feeding $(n=791)$} \\
\hline Human milk & $673(85 \%)$ \\
\hline Infant formula & $102(10 \%)$ \\
\hline Both & $16(2 \%)$ \\
\hline Skin-to-skin contact (usually $\leq 1.0 \mathrm{~h}$ ) & $673(68 \%)$ \\
\hline
\end{tabular}

Notes: 'Late preterm, $35^{0 / 7}$ to $36^{6 / 7}$ weeks' gestation. ' Seventeen (2\%) of these newborns were transferred to the NNU within $4 \mathrm{~h}$ after birth. Their blood glucose values were: mean $\pm S D$, I.4 \pm 0.4 ; median, I.2; range, $\leq 1.0$ to $2.3 \mathrm{mmol} / \mathrm{L}(\mathrm{n}=17)$. ${ }^{\mathrm{C}}$ Five of these newborns were transferred to the NNU between 4 and $24 \mathrm{~h}$ after birth for hypoglycemia after feeding; their blood glucose values were: mean $\pm S D, 2.1 \pm 0.2$; median, 2.I; range, 1.9 to $2.3 \mathrm{mmol} / \mathrm{L}(\mathrm{n}=5)$. Otherwise, the overall blood glucose values were: mean $\pm S D, 2.2 \pm 0.3$; median, 2.2; range, I.4 to $2.4 \mathrm{mmol} / \mathrm{L}(\mathrm{n}=42)$. ${ }^{\mathrm{d} S e v e n t e e n ~ n e w b o r n s ~}$ were admitted within $4 \mathrm{~h}$ after birth (footnote "b") and five newborns were admitted between 4 and $24 \mathrm{~h}$ after birth (footnote " $\mathrm{c}$ "). Their overall blood glucose values were: mean $\pm S D, 1.5 \pm 0.5$; median, I.3; range, $\leq 1.0$ to $2.3 \mathrm{mmol} / \mathrm{L}(\mathrm{n}=22)$. ${ }^{\mathrm{e}} T$ he remaining 192 newborns had blood glucose measurement before feeding.

a measurable amount [typically, 20 to $30 \mathrm{~mL}$ ] of freshly expressed breast milk or infant formula followed, $30 \mathrm{~min}$ later, by rechecking blood glucose). Forty-two (4.3\%) newborns had hypoglycemia within 4 to $24 \mathrm{~h}$. Five were transferred to the NNU for the same reason mentioned above. Thus, the 
overall prevalence of hypoglycemia in the first $24 \mathrm{~h}$ was $23.8 \%$, and that of NNU transfer $2.2 \%$. Nineteen of the 22 ("17 + 5") NNU transfers were IDM; six were receiving human milk, eight were receiving infant formula, and eight were receiving both.

Three of the 22 neonates who required NNU admission were symptomatic. One had lethargy and poor feeding and two had vomiting. Their clinical findings were resolved quickly after intravenous glucose administration. One more neonate had mild respiratory distress, which required support over 24 h. For the remaining 18 neonates, the hypoglycemia was asymptomatic, detected on the screening, and did not respond to the feeding trial (emphasizing the need for regular monitoring).

All of the 10 neonates with severe hypoglycemia (blood glucose $\leq 1.0 \mathrm{mmol} / \mathrm{L}$ ) required NNU transfer for intravenous glucose administration. Nine of them had normal development on the routine assessments at 2, 6, 12, 18 , and 24 months of age (unable to follow-up with one).

The multiple logistic regression model showed the overall independent predictors of NNU transfers were late-preterm $(P<0.018)$, cesarean delivery $(P<0.019)$, and glucose measurement $<1.5 \mathrm{~h}(P<0.017$, please see Figure 1A for the change in glucose level with age). Thus, clinical observation and close monitoring are needed for the infants with late preterm or cesarean delivery.

\section{Hypoglycemia}

The prevalence of hypoglycemia in the first $4 \mathrm{~h}$ was lower in newborns who had the first feeding $\leq 1.0 \mathrm{~h}(15.7 \%$ versus

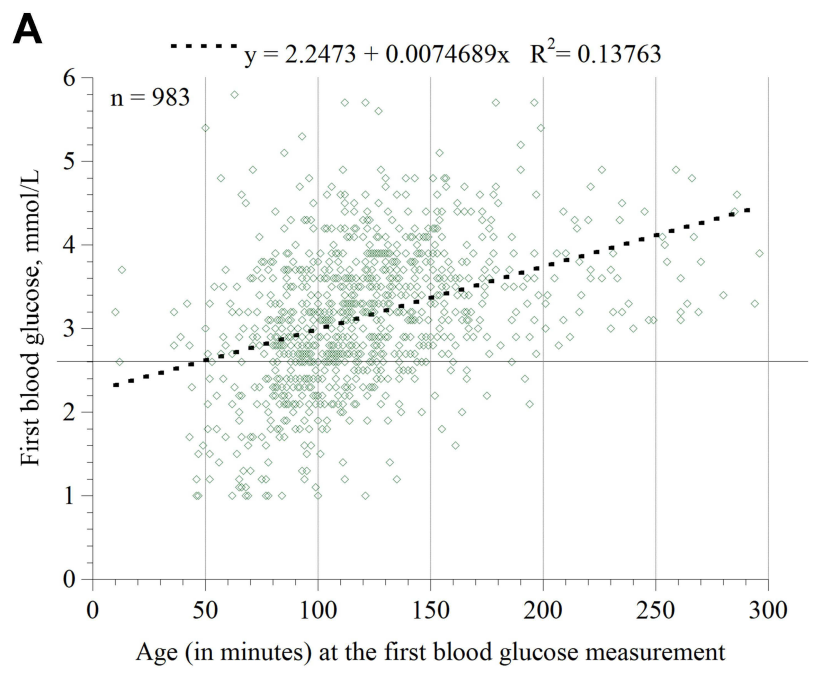

$28.8 \%, P<0.001)$, glucose measurement $>1.5$ h (13.9\% versus $39.7 \%, P<0.001$ ), glucose measurement after feeding (14.5\% versus $39.6 \%, P<0.001)$, and vaginal delivery (14.7\% versus $29.0 \%, P<0.001$ ), Figure 2. Higher numbers of risks were associated with higher frequencies of early hypoglycemia $(P=0.005)$.

It is worth noting that "first feeding $>1.0 \mathrm{~h}$ of life" was not a predictor of early hypoglycemia in the multiple logistic regression model (Table 2; the odds of hypoglycemia in infants who had the first feeding $>1.0$ h was $58 \%$ lower; please also see Figure 1B). Thus, main determinants of early hypoglycemia remain "late-preterm" and "cesarean delivery" (along with manipulating time of glucose measurements), Table 2. Similarly, the multiple logistic regression model showed the independent predictor of hypoglycemia between 4 and $24 \mathrm{~h}$ was cesarean delivery $(P=0.017$, Table 3$)$. It is also worth noting that IDM was negatively related to hypoglycemia between 4 and $24 \mathrm{~h}$ (a finding that was confirmed through cross-tabulation and simple logistic regression analyses). This result could reflect an improved awareness and care for these infants (Table 3).

\section{First Feeding}

Of the 983 newborns, $688(70 \%)$ received the first feeding $\leq 1.0 \mathrm{~h}$ of life and $295>1.0 \mathrm{~h}$ of life (Table 1 and Figure 2). The precise time (exact age) at first feeding, however, was available for only 574 newborns (58\%, Figures 3 and 1B, closed red diamonds). The time (mean $\pm \mathrm{SD}$ ) of the first feeding was $47 \pm 30 \mathrm{~min}$ (median, $41 \mathrm{~min}$; range, $1 \mathrm{~min}$ to $192 \mathrm{~min}$ ). (It is important to note that the multiple logistic

B Age (in minutes) at the first blood glucose measurement (open blue diamonds)

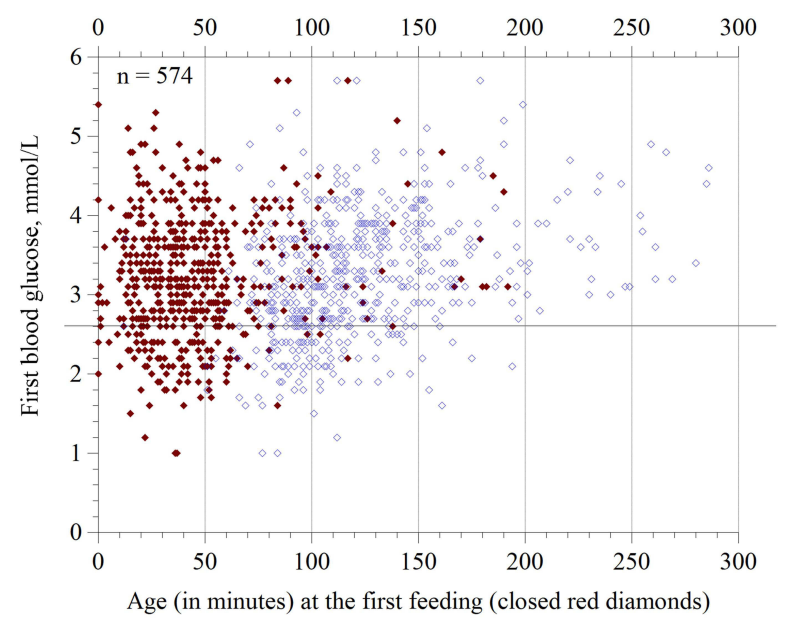

Figure I Scatter plots of the first glucose readings (in mmol/L). (A) First glucose readings as a function of "age at these measurements" ( $n=983$ ). The dotted line is linear fit; its equation is shown. The horizontal line is the cutoff $2.5 \mathrm{mmol} / \mathrm{L}$. (B) First glucose readings as functions of "age at the first feeding" (closed red diamonds) and "age at these measurements" (open blue diamonds). For these 574 infants, the time of first feeding was documented; two data points, 8.6 and 7.2 mmol/L, were removed to increase the clarity of the graph. 


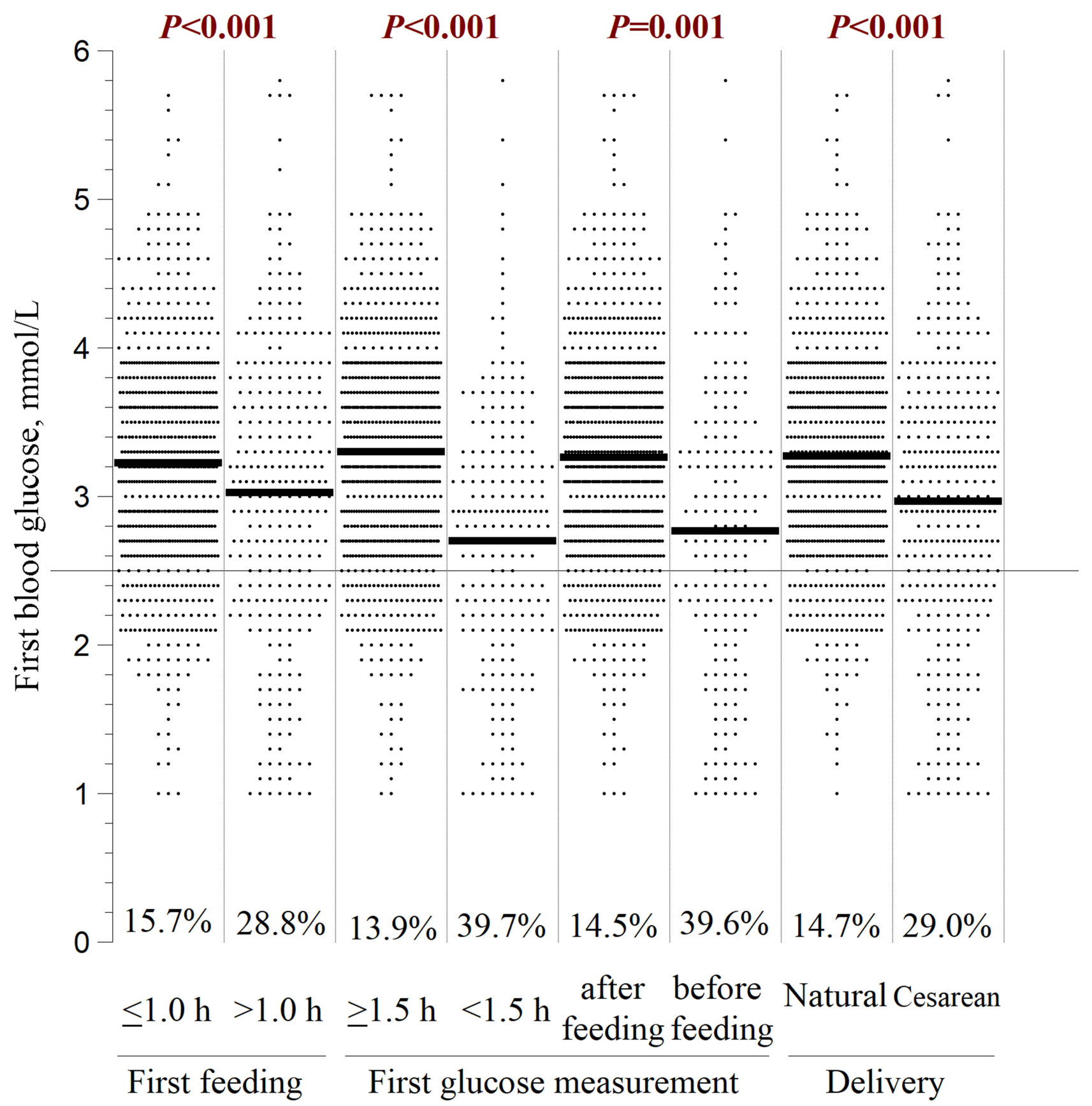

Figure 2 Dot Plot showing the first blood glucose values (mmol/L) within $4 \mathrm{~h}$ after birth as functions of first feeding ( $\leq \mathrm{I} .0 \mathrm{~h}$ versus $>\mathrm{I} .0 \mathrm{~h}$ ), first glucose measurement $(\geq 1.5 \mathrm{~h}$ versus $<1.5 \mathrm{~h}$, and before versus after feeding), and mode-of-delivery (vaginal versus caesarean). Percentages of infants with readings $<2.5 \mathrm{mmol} / \mathrm{L}$ and the corresponding $P$ (Pearson chi-square test) values between the groups are shown. Short bolded horizontal lines are mean. The cutoff $2.5 \mathrm{mmol} / \mathrm{L}$ is shown as a long horizontal line. Six blood glucose values $>6.0 \mathrm{mmol} / \mathrm{L}$ were removed to increase the clarity of the graph.

regression model in Table 2 was based on the 983 newborns. Therefore, the independent variables in the backward selection did not include the time of first feeding, which had many missing values.)

\section{First Glucose Readings}

The time (mean \pm SD) of the first glucose measurement was 121 $\pm 43 \mathrm{~min}$ (median, $115 \mathrm{~min}$; range, $10 \mathrm{~min}$ to $296 \mathrm{~min}$; $\mathrm{n}=932$ ),
Figure 3. Independent predictors of a low first glucose reading were late preterm $(P=0.002)$, cesarean delivery $(P=0.045)$, and glucose measured $<1.5 \mathrm{~h}$ of life or before feeding $(P<0.001)$, Table 2. The first glucose readings as a function of age is shown in Figure 1A; the increase in blood glucose with age is evident (approximately $0.45 \mathrm{mmol} \mathrm{L}^{-1} \mathrm{~h}^{-1}$, Pearson correlation, 0.934; $\left.R^{2}, 0.873 ; \mathrm{P}<0.001\right)$. One hundred ninety-two (19.5\%) of these infants had glucose levels $<2.5 \mathrm{mmol} / \mathrm{L}$. 
Table 2 Backward Multiple Logistic Regression (Likelihood Ratio) of Hypoglycemia Between 0 and 4 h of Age (the First Measurement) versus Various Variables

\begin{tabular}{|l|c|c|c|c|c|}
\hline & B & \multirow{2}{*}{ P } & \multirow{2}{*}{ Exp(B) } & \multicolumn{2}{|c|}{ 95\% C.I. for EXP(B) } \\
\cline { 3 - 5 } & & & & \multicolumn{2}{|c|}{ Lower Upper } \\
\hline First glucose measurement after feeding & -1.484 & 0.000 & 0.227 & 0.114 & $0.45 \mathrm{I}$ \\
First glucose measurement $>1.5 \mathrm{~h}$ after birth & -1.096 & 0.000 & 0.334 & 0.234 & 0.477 \\
Term & -0.633 & 0.002 & 0.531 & 0.359 & 0.785 \\
First feeding >I.0 h after birth & -0.869 & 0.018 & 0.419 & 0.204 & 0.860 \\
Vaginal delivery & -0.476 & 0.045 & 0.621 & 0.391 & 0.989 \\
\hline
\end{tabular}

Notes: The significant variables in simple logistic regressions of hypoglycemic status were entered in the backward multiple logistic regression models. Variables entered on step I: skin-to-skin, gender, birth weight ( $\mathrm{kg}$ ), IDM, feeding $\leq 1.0 \mathrm{~h}$, first blood glucose measurement $>1.5 \mathrm{~h}$ after birth, first blood glucose measurement after feeding, late preterm, and mode-of-delivery. The odds [likelihood ratio, $\operatorname{Exp}(\mathrm{B})$ ] of hypoglycemia in infants who had the first glucose measurement after feeding were $77 \%$ ( 1 minus 0.227 ) lower, glucose measurement $>1.5 \mathrm{~h} 67 \%$ lower, term pregnancy $47 \%$ lower, first feeding $>1.0 \mathrm{~h} 58 \%$ lower, and vaginal delivery $38 \%$ lower.

Table 3 Backward Multiple Logistic Regression (Likelihood Ratio) of Hypoglycemic Status Between 4 and 24 h of Age versus Various Variables

\begin{tabular}{|l|c|c|c|c|c|}
\hline & B & \multirow{2}{*}{$\boldsymbol{P}$} & \multirow{2}{*}{ Exp(B) } & \multicolumn{2}{|c|}{ 95\% C.I. for EXP(B) } \\
\cline { 3 - 5 } & & & & Lower & Upper \\
\hline IDM & -0.878 & 0.008 & 0.416 & 0.218 & 0.793 \\
Caesarean delivery & 0.773 & 0.017 & 2.167 & 1.150 & 4.083 \\
Male & 0.561 & 0.098 & 1.752 & 0.902 & 3.403 \\
Constant & -3.197 & 0.372 & 73.882 & & \\
\hline
\end{tabular}

Notes: The significant variables in simple logistic regressions of hypoglycemic status were entered in the backward multiple logistic regression models. A backward multiple logistic regression of the status of hypoglycemia between 4 and $24 \mathrm{~h}$ versus the predictors IDM, late preterm, mode-of-delivery, birthweight, and gender was executed. Significant predictors that remained in the model were IDM, mode-of-delivery, and gender. The odds of hypoglycemia among IDM are $58 \%$ lower, while controlling for the mode-of-delivery and gender. After controlling for IDM and gender, the odds of hypoglycemia are II7\% higher for infants born by caesarean section. The odds of hypoglycemia are also $75 \%$ higher for males as compared to females.

The time of the first feeding was documented in 574 infants; for these infants, the first glucose readings were plotted in Figure 1B as functions of "age at the first feeding" and "age at these measurements". Ninety $(15.3 \%)$ infants had blood glucose levels of $<2.5 \mathrm{mmol} / \mathrm{L}$. The increase in glucose levels with age is also evident (Pearson correlation, 0.798; $\left.R^{2}, 0.637 ; P<0.001\right)$. As shown in Figure $1 \mathrm{~B}$, the time of the first feeding had a lesser effect on the glucose level compared to the age of the glucose measurement.

\section{Discussion}

This study assessed the feeding and glucose monitoring practices in our level-1 postnatal unit. Its main purposes were to improve the care and lower the rate of $\mathrm{NNU}$ transfer for neonates with hypoglycemia. Being the only tertiary-care center for high-risk pregnancies in Al Ain City, the prevalence of IDM in the studied infants was remarkably high. The key findings here are summarized as follows: (1) Late-preterm infants and those of cesarean delivery need careful care, similar to that of IDM. (2)
High prevalence $(23.8 \%)$ of low glucose readings $(<2.5$ $\mathrm{mmol} / \mathrm{L}$ ) in at-risk infants, especially in the first $4 \mathrm{~h}$ of life. This finding emphasizes the need to establish reference blood glucose values that define "hypoglycemia" as a function of age, despite the valid need for "operational glucose levels". (3) Relatively high rate of NNU transfer in the first $4 \mathrm{~h}$, which emphasizes the need for a closer observation during this transitional period. (4) Lack of (or subtle) clinical findings in the majority of infants who had severe hypoglycemia or required NNU transfer, which emphasizes the need for regular monitoring for all at-risk infants. (5) Improved awareness and clinical care for atrisk infants can ameliorate the risk of hypoglycemia, as noted here in IDM. Future studies are needed to understand the mechanism(s) of hypoglycemia in infants who failed a feeding trial. Therefore, it is readily evident that recognizing infants at risk of hypoglycemia and adhering to the evidence-based feeding and monitoring guidelines are sensible. It is also important to extend the list of infants at risk of hypoglycemia by recognizing other variables, 


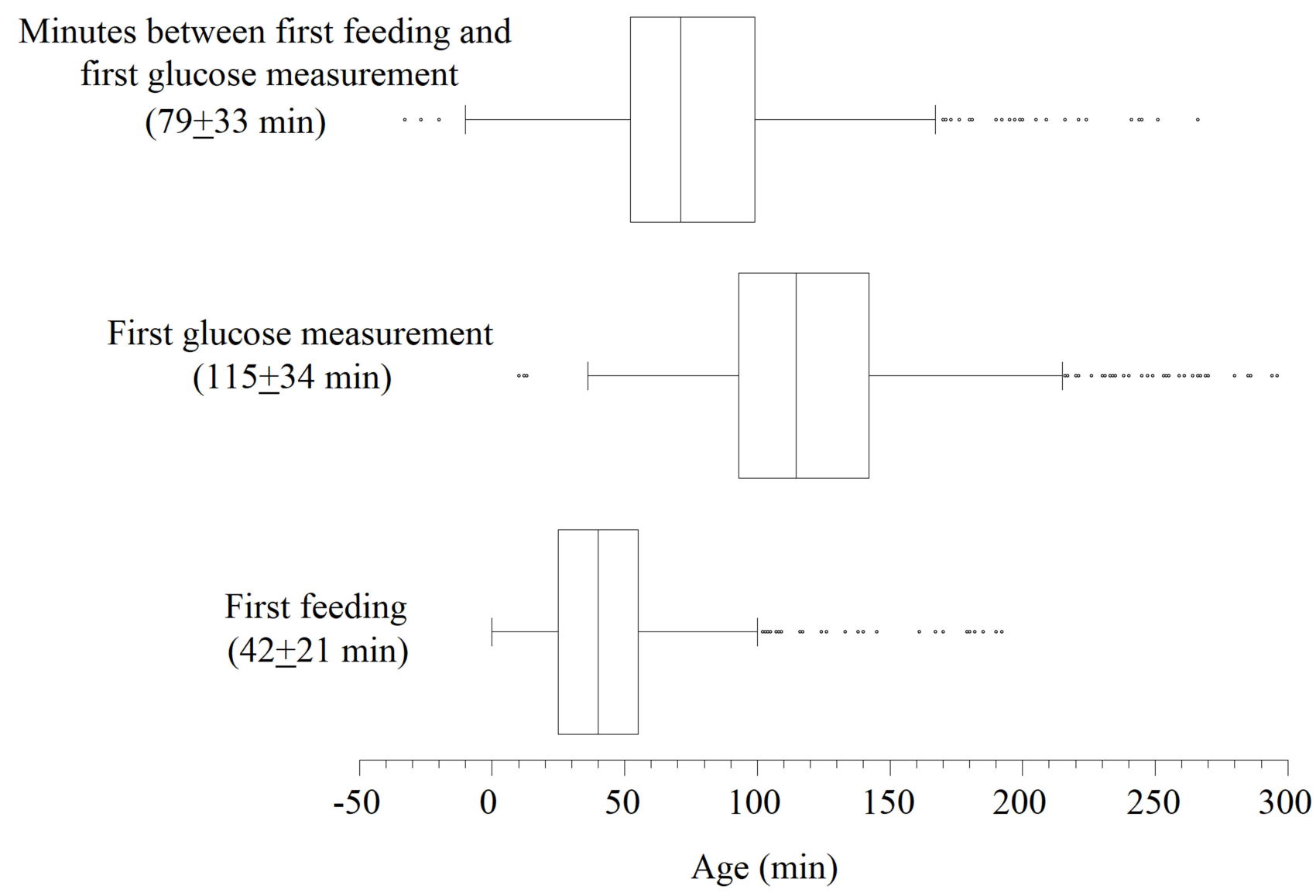

Figure 3 Box plots showing the distributions of age (in $\min$ ) at the first feeding ( $n=574,58 \%)$, at the first blood glucose measurement $(n=932,95 \%)$, and the minute-intervals between them; all based on "minimum, first quartile, median, third quartile, maximum, and outliers". For age at the first feeding, 20 values (one at 355 min and 19 at 0 min) were charting errors (removed); moreover, the exact age at the first feeding was not charted in 409 newborns. For age at the first measurement, 37 values were $>6 \mathrm{~h}$ (removed to increase the clarity of the graph) and 14 were charting errors (removed).

such as maternal obesity, maternal medications, congenital disorders, and genetic syndromes. ${ }^{4}$

As previously shown, the blood glucose may drop to 1.1 to $1.4 \mathrm{mmol} / \mathrm{L}$ between 1.0 and $1.5 \mathrm{~h}$ of life in low-risk newborns. ${ }^{8}$ Readings then increase gradually with time, even if the first feeding is slightly delayed. ${ }^{12}$ This "transitional low blood glucose" should be coupled to lower insulin and higher glucagon blood levels. ${ }^{13}$ Other protecting hormones include cortisol, growth hormone, and catecholamines. $^{14}$ Early feeding (within $60 \mathrm{~min}$ after birth) could be essential for certain infants, such IDM, low birthweight, SGA, late preterm, and other not yet well-defined clinical conditions. ${ }^{3,7}$ Therefore, adhering to the guidelines of "early initiation and maintaining a proper feeding" is crucial for all neonates, especially those with identifiable risk variables. This awareness is critical, principally with respect to the well-documented adverse events of hypoglycemia on neurodevelopment. ${ }^{8-11}$

Valid glucose measurements are essential for proper interpretation. The analytical tool should be accurate over the range
0 to $5.0 \mathrm{mmol} / \mathrm{L}$, and the test should be simple (convenient for the nurses) and quick (essential for prompt management). Low readings should be confirmed by an easily accessible "blood gas analyzer", preferably inside the PNU. ${ }^{15-17}$

In one prospective study, the incidence of blood sugar $\leq 2.0$ $\mathrm{mmol} / \mathrm{L}$ was $19 \%$, and was mostly observed in the first $24 \mathrm{~h}^{18}$ In another prospective study involving healthy newborns, blood glucose $<2.6 \mathrm{mmol} / \mathrm{L}$ was more frequent in those who had a delayed initiation of breastfeeding, with an overall incident of $2.2 \%$ in the first three days. ${ }^{19}$ In a retrospective study, the nadir of plasma glucose in late-preterm infants was similar to that in term infants (mean, $\sim 90 \mathrm{~min}$ ). ${ }^{20}$

\section{Summary of the Study Strengths and Limitations}

The study was conducted in the main tertiary-care center in the region, having a large proportion of high-risk pregnancies (including newborns with IDM, late-preterm, and caesarian delivery). The prevalence of severe hypoglycemia (blood 
glucose $\leq 1.0 \mathrm{mmol} / \mathrm{L}$ ), symptomatic newborns, or NNU transfer was relatively low. The number $(n=983)$ and percentage (38\% of the total PNU admissions) of enrolled neonates were large. The distribution of the risk variables among studied neonates is also proper. These characteristics allowed reliable multiple logistic regression analyses for both early hypoglycemia and that between 4 and $24 \mathrm{~h}$ of life. The study was conducted over an entire calendar year. Limitations include being retrospective and did not include relevant variables, such as maternal conditions (eg, excess body fat, medications, and systemic illnesses), important neonatal conditions (eg, small-for-gestational-age [SGA], intrauterine growth restriction [IUGR], and genetic syndromes). The sensitivity of glucometers was not compared to that of plasma glucose. ${ }^{21}$ The neonates with severe hypoglycemia were not referred for comprehensive neurodevelopmental evaluation as recommended. ${ }^{17}$ Practice gaps also included incomplete charting and partial adherence to the monitoring and feeding protocols.

The study enrolled only newborns in the level-1 PNU who were eligible for regular glucose monitoring, as specified in Methods. According to our hospital policy, these infants are $\geq 35$ weeks' gestation and $\geq 2.0 \mathrm{~kg}$ birthweight (10th centile for 35 weeks' gestation). Thus, true "IUGR" and "SGA" newborns were not identified in this study. Future studies are needed to address such clinical conditions. The insufficient information about our practice of skin-to-skin contact prevented proper interpretation of its benefits in at-risk infants. The "glucose gel" has recently being used in our PNU (see Supplementary File), and future studies are needed to assess its impact on the prevalence and outcome of hypoglycemia. ${ }^{10}$ Finally, regular staff training and outcome assessment are core to establishing and maintaining optimal management of blood glucose in the newborn.

In conclusion, identifying infants at risk of hypoglycemia in the level-1 postnatal unit is crucial. The attentiveness to close clinical observation, initiating and maintaining proper feeding, and regular glucose monitoring is also vital. Independent predictors of NNU transfer for hypoglycemia include late-preterm and caesarian delivery. Special care for these infants is needed to prevent adverse neurodevelopmental outcomes.

\section{Acknowledgment}

The authors acknowledge the unmatched contributions of all Tawam staff in the postnatal unit.

\section{Funding}

There is no funding to report.

\section{Disclosure}

The authors declare that they have no conflicts of interest for this work.

\section{References}

1. Thompson-Branch A, Havranek T. Neonatal hypoglycemia. Pediatr Rev. 2017;38(4):147-157. doi:10.1542/pir.2016-0063

2. LeBlanc S, Haushalter J, Seashore C, Wood KS, Steiner MJ, Sutton AG. A quality-improvement initiative to reduce NICU transfers for neonates at risk for hypoglycemia. Pediatrics. 2018;141(3): e20171143. doi: 10.1542/peds.2017-1143

3. Zhou Y, Bai S, Bornhorst JA, Elhassan NO, Kaiser JR. The effect of early feeding on initial glucose concentrations in term newborns. J Pediatr. 2017;181:112-115. doi:10.1016/j.jpeds.2016.10.032

4. Turner D, Monthé-Drèze C, Cherkerzian S, Gregory K, Sen S. Maternal obesity and cesarean section delivery: additional risk factors for neonatal hypoglycemia? J Perinatol. 2019;39(8):1057-1064. doi:10.1038/s41372-019-0404-z

5. Adamkin DH; Committee on Fetus and Newborn. Postnatal glucose homeostasis in late-preterm and term infants. Pediatrics. 2011;127 (3):575-579. doi:10.1542/peds.2010-3851

6. Narvey MR, Marks SD. The screening and management of newborns at risk for low blood glucose. Paediatr Child Health. 2019;24 (8):536-554. doi:10.1093/pch/pxz134

7. Wight NE, Wight NE, Stehel E; Academy of Breastfeeding Medicine. $\mathrm{ABM}$ clinical protocol \#1: guidelines for glucose monitoring and treatment of hypoglycemia in term and late preterm neonates, revised 2021. Breastfeed Med. 2021;16(5):353-365. doi:10.1089/ bfm.2021.29178.new

8. McKinlay CJD, Alsweiler JM, Anstice NS, et al; Children With Hypoglycemia and Their Later Development (CHYLD) Study Team. Association of neonatal glycemia with neurodevelopmental outcomes at 4.5 years. JAMA Pediatr. 2017;171(10):972-983. doi:10.1001/jamapediatrics.2017.1579

9. McKinlay CJ, Alsweiler JM, Ansell JM, et al; CHYLD Study Group. Neonatal glycemia and neurodevelopmental outcomes at 2 years. $N$ Engl J Med. 2015;373(16):1507-1518. doi:10.1056/NEJM oa1504909

10. Harris DL, Alsweiler JM, Ansell JM, et al; Children with Hypo glycaemia and their Later Development (CHYLD) Study Team. Outcome at 2 years after dextrose gel treatment for neonatal hypoglycemia: follow-up of a randomized trial. J Pediatr. 2016;170:54-9. e1-2. doi:10.1016/j.jpeds.2015.10.066

11. Mahajan G, Mukhopadhyay K, Attri S, Kumar P. Neurodevelopmental outcome of asymptomatic hypoglycemia compared with symptomatic hypoglycemia and euglycemia in high-risk neonates. Pediatr Neurol. 2017;74:74-79. doi:10.1016/j. pediatrneurol.2017.05.028

12. Srinivasan G, Pildes RS, Cattamanchi G, Voora S, Lilien LD. Plasma glucose values in normal neonates: a new look. J Pediatr. 1986;109 (1):114-117. doi:10.1016/s0022-3476(86)80588-1

13. Stanley CA, Rozance PJ, Thornton PS, et al. Re-evaluating "transitional neonatal hypoglycemia": mechanism and implications for management. $\quad J \quad$ Pediatr. 2015;166(6):1520-5.e1. doi:10.1016/j. jpeds.2015.02.045

14. Tas E, Garibaldi L, Muzumdar R. Glucose homeostasis in newborns: an endocrinology perspective. Neoreviews. 2020;21(1):e14-e29. doi:10.1542/neo.21-1-e14 
15. Dalsgaard BT, Rodrigo-Domingo M, Kronborg H, Haslund $\mathrm{H}$. Breastfeeding and skin-to-skin contact as non-pharmacological prevention of neonatal hypoglycemia in infants born to women with gestational diabetes; a Danish quasi-experimental study. Sex Reprod Healthc. 2019;19:1-8. doi:10.1016/j.srhc.2018.10.003

16. Adamkin DH. Neonatal hypoglycemia. Semin Fetal Neonatal Med. 2017;22(1):36-41. doi:10.1016/j.siny.2016.08.007

17. Shah R, Harding J, Brown J, McKinlay C. Neonatal glycaemia and neurodevelopmental outcomes: a systematic review and meta-analysis. Neonatology. 2019;115(2):116-126. PMID: 30408811. doi:10.1159/000492859

18. Harris DL, Weston PJ, Harding JE. Incidence of neonatal hypoglycemia in babies identified as at risk. J Pediatr. 2012;161(5):787-791. doi:10.1016/j.jpeds.2012.05.022
19. Mukunya D, Odongkara B, Piloya T, et al. Prevalence and factors associated with neonatal hypoglycemia in Northern Uganda: a community-based cross-sectional study. Trop Med Health. 2020;48 (1):89. doi:10.1186/s41182-020-00275-y

20. Kaiser JR, Bai S, Rozance PJ. Newborn plasma glucose concentration Nadirs by gestational-age group. Neonatology. 2018;113 (4):353-359. doi:10.1159/000487222

21. Ho HT, Yeung WK, Young BW. Evaluation of "point of care" devices in the measurement of low blood glucose in neonatal practice. Arch Dis Child Fetal Neonatal Ed. 2004;89(4):F356-F359. doi:10.1136/ adc. 2003.033548

22. Carreiro MP, Nogueira AI, Ribeiro-Oliveira A. Controversies and advances in gestational diabetes-an update in the era of continuous glucose monitoring. J Clin Med. 2018;7(2):11. doi:10.3390/jcm7020011

\section{Publish your work in this journal}

Research and Reports in Neonatology is an international, peerreviewed, open access journal publishing original research, reports, editorials, reviews and commentaries on neonatal health. The manuscript management system is completely online and includes a very quick and fair peer-review system. Visit http://www.dovepress. com/testimonials.php to read real quotes from published authors. 